\title{
The use of progressive muscle relaxation with classical music in hypertension women
}

\author{
Agustina Boru Gultom, Arbani Batubara \\ Health Polytechnic, Health Ministry Medan, North Sumatera, Indonesia
}

Received: March 2, 2021

DOI: $10.5430 /$ jnep.v11n9p44
Accepted: May 5, 2021

URL: https://doi.org/10.5430/jnep.v11n9p44

\begin{abstract}
Background/Objective: Hypertension is still a public health problem both in the world and in Indonesia. Even though women with hypertension are already taking antihypertensive drugs, often blood pressure remains high. Women are more likely to be stressed, and stress increases hypertension. The study aimed to analyze the use of progressive muscle relaxation with classical music on stress and blood pressure in hypertensive women.

Methods: This study used a quasi-experimental design with a control group. There were three groups of hypertensive women who took anti-hypertensive drugs, consisting of those who received progressive muscle relaxation with classical music, accepted progressive muscle relaxation without classical music, and did not get treatment, each of which totaled 36 participants. The activity was carried out from July to October 2020. The stress instrument used was the Cohen's Perceived Stress Scale, while blood pressure was measured with the OMRON digital tensimeter.

Results: The group that received progressive muscle relaxation with classical music from Bach described high significance for stress $(p=.0001)$, systolic $(p=.0001)$, diastolic $(p=.0001)$. The group that received progressive muscle relaxation alone also showed high significance for stress $(p=.010)$, systolic $(p=.003)$, diastolic $(p=.006)$. While the untreated group showed significance for systolic ( $p=.013)$, but did not show significance for stress $(p=.758)$, diastolic $(p=.123)$. The use of ANOVA showed a significant difference in the effect of the three intervention on stress $(p=.005)$, systolic blood pressure $(p=.009)$, but did not have a significant effect on diastolic blood pressure $(p=.500)$.

Conclusions: Progressive muscle relaxation with classical music and antihypertensive drugs provides a greater chance of controlling stress, lowering systolic and diastolic blood pressure than just progressive muscle relaxation and antihypertensive drugs or antihypertensive drugs alone in women with hypertension.
\end{abstract}

Key Words: Progressive muscle relaxation, Classical music, Stress, Blood pressure, Hypertension

\section{INTRODUCTION}

Hypertension is still a public health problem that occurs in all parts of the world. ${ }^{[1,2]}$ This problem contributes to the emergence of heart problems, stroke, and kidney failure and causes disability, and accelerates death. Raising awareness is key in achieving early recognition of these problems. ${ }^{[3]}$ ering blood pressure both in collective action in society and individually through behavior and medication. It can be illustrated that efforts to reduce systolic blood pressure by 10 $\mathrm{mmHg}$ will correlate with approximately $22 \%$ reduction in coronary heart disease and $41 \%$ reduction in stroke disease, and $41 \%-46 \%$ less death due to metabolic heart disease. ${ }^{[4]}$

Several studies have shown consistent health benefits in low- Many women suffer from hypertension and stress has been

\footnotetext{
*Correspondence: Agustina Boru Gultom; Email: agustinagultom203@gmail.com; Address: Health Polytechnic, Health Ministry Medan, North Sumatera, Indonesia.
} 
linked with the incidence of hypertension. Previous studies have shown that $84 \%$ of black women have hypertension and $59 \%$ have a poor lifestyle regarding diet and physical activity and are more likely to experience stress and hypertension. ${ }^{[5]}$ Another study also shows that women who experience stress tend to have hypertension by $76 \%$ compared to do not experience it and there is a relationship between stress and the incidence of hypertension $(p=.001) .{ }^{[6]}$

Stress can present a variety of actions on the body, starting from changes in balance to events that disrupt a person's life and even death. ${ }^{[7]}$ Stress causes an increase in the work of the sympathetic system, excess glucocorticoids and, changes in endothelial function, including a decrease in the availability of nitric oxide as a regulator in the stress system which affects blood pressure and vascular function. ${ }^{[8]}$

The body that responds to stress will work well for individuals who are relatively young, healthy, optimistic and, have a good defense response mechanism, and ability to take advantage of the stress experiences that occur. However, if the individuals have veryhigh stress, there must be a serious effort, influenced by factor age, genetics, and the increasing pressure on the existing rules, so that stress can cause disease. ${ }^{[9]}$

Acute stress can increase blood pressure, and the more stress experienced will be associated with a continuous increase in blood pressure and the incidence of hypertension. ${ }^{[10]}$ The increase in stress from one period to another will be associated with an increase in hypertension problems. ${ }^{[11]}$ Chronic stress affects not only the form of action such as depression but also autonomic baroreflex reactions and cardiovascular diversity including systolic blood pressure and interval pulse rates. ${ }^{[12]}$

One effort that can be offered to reduce stress and blood pressure is progressive muscle relaxation. ${ }^{[13]}$ This technique is a combination of taking a deep breath and a series of tenses and relaxes muscles which can reduce stress stabilize blood pressure in hypertensive patients who use anti-hypertensive drugs. ${ }^{[14]}$ These interventions can reduce stress perceptions and increase their perceptions of being healthy and have utility in patients with essential hypertension. ${ }^{[15]}$

On the other hand, there is also research on interventions that can lower blood pressure by using a combination of listening to music and deep breathing exercises where it was found that deep breathing exercise did not provide benefits for music in minimizing blood pressure. ${ }^{[16]}$ The intervention is a safe, economical cost, can be well designed, and has high quality and can contribute to the reduction of blood pressure in hypertensive patients. ${ }^{[17]}$ Music can be a medium for heal-

Published by Sciedu Press ing based on the law of rhythm and harmonious vibration. ${ }^{[18]}$ The use of music can reduce blood pressure achieved through slow breathing efforts so that a low baroreflex sensitivity is followed by an increase in parasympathetic tone. ${ }^{[19]}$

Efforts to provide classical music can lower blood pressure in children. ${ }^{[20]}$ Music such as classic music provides motivation, a feeling of comfort, and healing for patients who hear it. $^{[21]}$ Bach did not use tones with great power, but with deep feelings, in the form of simple and harmonious melodies, relying more on art than the music itself. ${ }^{[22]}$ The power of Bach's musical trend provides an impact on cardiovascular indicators in the form of blood pressure and pulse. ${ }^{[23]}$

Progressive muscle relaxation and classical music from Bach should be combined to control stress and blood pressure. One study showed that music, as well as progressive muscle relaxation can reduce depression, anxiety, and length of stay in female breast cancer patients after breast removal. ${ }^{[24]}$

A preliminary survey at Puskesmas Mulyorejo and Puskesmas Tuntungan, Deli Serdang Regency, found that hypertension was one of the top 10 diseases with the most cases, and the presence of hypertensive patients experiencing tension or stress in their daily lives.

Therefore, the study aimed to analyze the effect of progressive muscle relaxation with and without classical music on stress and blood pressure in women with hypertension.

\section{METHODS}

\subsection{Ethical considerations}

This research has received approval from the research ethics committee of the Health Polytechnic of the Ministry of Health Medan with the number 01.293/KEPK/POLTEKKES KEMENKES MEDAN 2020.

\subsection{Design}

A quantitative study using a quasi-experimental design with three types of groups including the progressive muscle relaxation treatment group with classical music, only progressive muscle relaxation, and a control group. The research was carried out in the work area of Puskesmas Mulyorejo dan Puskesmas Tuntungan, Deli Serdang Regency from July to October 2020.

\subsection{Participants}

The participants were hypertension patients who seek treatment at Puskesmas Mulyorejo and Puskesmas Tuntungan Deli Serdang Regency. The study used consecutive sampling. The inclusion criteria include: a) women diagnosed with hypertension, b) using at least 1 type of hypertension drug, c) body temperature during activity $\leq 37^{\circ}$ Celsius (due to 
the Covid-19 pandemic situation), d) age $\geq 18$ years, e) full awareness, not disoriented, able to communicate well, and willing to be participants.

\subsection{Sample size}

Measured by the minimum single sample formula in hypothesis testing using the correlation coefficient, 36 participants were obtained for each group, for a total of 108 participants.

\subsection{Intervention}

Progressive muscle relaxation carried out became a modification of the intervention from Edmund Jacobson, covering movements consisting of the 15 muscles including the hands, forearms, upper arms, shoulders, forehead, eyes, cheeks, and jaw, mouth, back neck, front neck, back, chest, stomach, legs, and thighs were done each 2 times each movement.

Before the intervention, progressive muscle relaxation was started with deep breathing exercises by inhaling through the nose, then holding the breath for about 7 seconds, then exhaling slowly through the mouth for about 20 seconds Classical music in the form of classical music from Johan Sebastian Bach which has been packaged with the number E045. These interventions have been facilitated by having modules, leaflets, availability of a laptop, external compact disc, and speakers during the exercise. To maintain the consistency of each intervention, the training was carried out by the same person. Participants in this study were selected based on existing inclusion criteria and were not random. Participants were divided into 3 groups based on the location of the study.

Group A came from patients in the village of Purwodadi in the work area of the Mulyorejo Public Health Center, Deli Serdang Regency.

Group A intervention in the form of progressive muscle relaxation with Bach classical music began with the provision of information about stress management, progressive muscle relaxation with classical music from Bach.

Group B came from patients in the village of Pujimulyo in the work area of the Mulyorejo Public Health Center, Deli Serdang Regency.

Group B intervention in the form of progressive muscle relaxation begins with providing information about stress management, progressive muscle relaxation. Each intervention was carried out within 2.5 hours at a time with guidance, and respondents were invited to carry it out every day at home.

Group $\mathrm{C}$ came from patients in the village of Hulu in the work area of the Tuntungan Public Health Center, Deli Serdang Regency. Group $\mathrm{C}$ was the group that did not get any treatment.

\subsection{Measurement}

Stress is defined as the extent to which the respondent experiences an unpredictable, unmanageable, and overloaded condition, measured using the Perceived Stress Scale questionnaire with 10 questions containing 5 answer interval from 0 to 4 , consisting of $0=$ never, $1=$ rarely, $2=$ sometimes, $3=$ often, 4 = veryoften.

The higher the stress score received is the same as the higher the person's feelings about stress. ${ }^{[25]}$ Cohen's perceived stress scale instrument is valid and reliable with Cronbach's Alpha > 0.7. ${ }^{[26]}$ Stress measurement was done by asking respondents about their perceived stress perception using the questionnaire provided. Blood pressure is defined as systolic measured when the sound of blood vessels expanding suddenly after collapsing and diastolic is at the time of loss of sound, with a digital tensimeter brand OMRON.

\subsection{Data collection}

After obtaining permission, the search for respondents began by looking at the data on the names of hypertensive patients in the records at the Puskesmas, then together with health workers planned to take research samples. At the time of data collection, the researcher explained the benefits of the research, the research procedure to prospective respondents to take part in the research, and those who were willing to participate were asked to sign the consent form. Respondents were measured stress using a questionnaire and blood pressure using a digital tensimeter brand OMRON. There were 3 groups of respondents in the study. The first group referred to as group A received 2 types of intervention in the form of progressive muscle relaxation and Bach music as classical music to accompany progressive muscle relaxation. The intervention in the form of exercise was carried out of 2 times in 3 weeks. ${ }^{[14]}$ The first exercise was carried out in the first week and the second exercise was carried out in the third week, each of which lasts 2.5 hours. In the first exercise, respondents were reminded to perform progressive muscle relaxation using Bach music which was given to respondents in the form of a Compact Disc CD every day at home.

The second group called group B received 1 type of intervention in the form of progressive muscle relaxation. The intervention in the form of exercise was carried out of 2 times in 3 weeks. The first exercise was carried out in the first week and the second exercise was carried out in the third week, each of which had a duration of 2.5 hours. In the first exercise, respondents were reminded to do progressive muscle relaxation every day at home. ${ }^{[14]}$

The third group was called group $\mathrm{C}$ who did not receive any 
intervention. Participants in this group received measurements before and after the study period for stress and blood pressure where were taken before the first week and after the study period was carried out in the fifth week using the same questionnaire and tools.

Each group numbered 36 respondents. Due to the Covid19 Pandemic situation, each large group was divided into 6 small groups, each of which numbered 6 participants, whose implementation time has been determined. Before the participants took part in the exercise, they were educated on how to wash their hands, invited to wash their hands with soap, use a mask, and have their body temperature measured to avoid transmission of Covid 19 between them and between participants and researchers.

Group A intervention in the form of progressive muscle relaxation with classical music from Bach began with the provision of information about stress management, progressive muscle relaxation with classical music from Bach. Group $\mathrm{B}$ intervention in the form of progressive muscle relaxation begins with providing information about stress management, progressive muscle relaxation.

\subsection{Data analysis}

Collected data were processed statistically using IBM SPSS statistics 22 software including univariate analysis in the form of participant characteristics, minimum values, maximum values, mean and standard deviation, and bivariate data analysis to analyze the effect of progressive muscle relaxation with and without classical music on stress, women's blood pressure, hypertensive patients with $t$-test and differences test with Oneway Anova if the data were normally distributed.

\section{Results}

\subsection{Participant characteristics}

One hundred and eight hypertensive women taking antihypertensive drugs showed interest in joining this study. 72 participants came from the Mulyorejo Health Center work area consisting of 36 who took part in the progressive muscle relaxation intervention with classical music, and 36 who only participated in progressive muscle relaxation. The other 36 participants came from the Tuntungan Health Center work area who did not receive treatment.

The majority of women with hypertension aged 60-74 years were 51 respondents $(47.2 \%), 63(58.3 \%)$ were married, 45 $(41.7 \%)$ had elementary education, $84(77.8 \%)$ had a monthly income of $\leq 2.132 .188$ rupiah, 62 (57.4\%) had experienced hypertension for less than 1 year Table 1 .
Table 1. Distribution of participants characteristics

\begin{tabular}{|c|c|c|}
\hline Variable & Frequency & Percentage (\%) \\
\hline \multicolumn{3}{|l|}{ Age } \\
\hline $35-44$ & 3 & 2.8 \\
\hline $45-59$ & 49 & 45.4 \\
\hline $60-74$ & 51 & 47.2 \\
\hline $75-90$ & 5 & 4.6 \\
\hline Total & 108 & 100.0 \\
\hline \multicolumn{3}{|l|}{ Marriage } \\
\hline Single & 11 & 10.2 \\
\hline Married & 63 & 58.3 \\
\hline Widow & 34 & 31.5 \\
\hline Total & 108 & 100.0 \\
\hline \multicolumn{3}{|l|}{ Education } \\
\hline Not School yet & 10 & 9.3 \\
\hline Primary School & 45 & 41.7 \\
\hline Junior High School & 18 & 16.7 \\
\hline Senior High School & 29 & 26.9 \\
\hline Collage & 6 & 5.6 \\
\hline Total & 108 & 100.0 \\
\hline \multicolumn{3}{|l|}{ Income $\{$ Rupiah\} } \\
\hline$\leq 2,132,188$ & 84 & 77.8 \\
\hline$>2,132,188-4,500,000$ & 20 & 18.5 \\
\hline$>4,500,000$ & 4 & 3.7 \\
\hline Total & 108 & 100.0 \\
\hline \multicolumn{3}{|l|}{ Type of Work } \\
\hline Housewife & 80 & 74,1 \\
\hline Private Employees & 3 & 2.8 \\
\hline Civil Servants/State-Owned Enterprises & 1 & 0.9 \\
\hline Entrepreneur & 17 & 15.7 \\
\hline Pension & 4 & 3.7 \\
\hline Another Job & 3 & 2.8 \\
\hline Total & 108 & 100.0 \\
\hline \multicolumn{3}{|l|}{ Long Time Suffering From Hypertension } \\
\hline$<1$ Year & 62 & 57.4 \\
\hline$\geq 1-<5$ Years & 32 & 29.6 \\
\hline$\geq 5-<10$ Years & 11 & 10.2 \\
\hline$\geq 10-<15$ Years & 2 & 1.9 \\
\hline$\geq 20$ Years & 1 & 0.9 \\
\hline Total & 108 & 100.0 \\
\hline
\end{tabular}

\subsection{Stress and blood pressure}

The mean stress score of the group receiving 2 treatments was 23.33 and after that was 18.22 . The mean stress score for the group before receiving 1 treatment was 18.08 and after that was 16.78. And, the mean stress score of the control group before the intervention period was 19.50, and after that was 19.31. The mean systolic score of the group before receiving 2 treatments was $158.06 \mathrm{mmHg}$ and after that was $142.55 \mathrm{mmHg}$. The mean systolic score of the group before receiving 1 treatment was $157.25 \mathrm{mmHg}$ and after that was $154.22 \mathrm{mmHg}$. And, the mean systolic score of the control group before the intervention period was 159.69 $\mathrm{mmHg}$, and after that was $153.19 \mathrm{mmHg}$. The mean diastolic score before receiving the 2 treatments was $97.97 \mathrm{mmHg}$ and after that was $88.56 \mathrm{mmHg}$. The mean diastolic score of the group before receiving 1 treatment was $92.64 \mathrm{mmHg}$ and after that was $90.97 \mathrm{mmHg}$. And, the mean diastolic score of 
the control group before the intervention period was 93.33 $\mathrm{mmHg}$ and after that was $90.44 \mathrm{mmHg}$ Table 2.

Table 2. Stress, systolic, and diastolic blood pressure

\begin{tabular}{lllll}
\hline Score & Min & Max & Mean & SD \\
\hline Stress Group I Pre & 18 & 30 & 23.33 & 2.43 \\
Stress Group I Post & 11 & 24 & 18.22 & 3.49 \\
Stress Group II Pre & 13 & 23 & 18.08 & 3.06 \\
Stress Group II Post & 8 & 22 & 16.78 & 3.55 \\
Stress Group III Pre & 12 & 29 & 19.50 & 3.57 \\
Stress Group III Post & 14 & 25 & 19.31 & 2.46 \\
Systolic Group I Pre & 140 & 208 & 158.06 & 16.05 \\
Systolic Group I Post & 122 & 166 & 142.55 & 12.14 \\
Systolic Group II Pre & 140 & 213 & 157.25 & 21.57 \\
Systolic Group II Post & 131 & 210 & 154.22 & 21.43 \\
Systolic Group III Pre & 140 & 207 & 159.69 & 18.75 \\
Systolic Group III Post & 127 & 188 & 153.19 & 15.50 \\
Diastolic Group I Pre & 90 & 145 & 97.97 & 10.00 \\
Diastolic Group I Post & 78 & 103 & 88.56 & 6.48 \\
Diastolic Group II Pre & 78 & 137 & 92.64 & 11.95 \\
Diastolic Group II Post & 80 & 135 & 90.97 & 11.43 \\
Diastolic Group III Pre & 78 & 120 & 93.33 & 8.12 \\
Diastolic Group III Post & 71 & 115 & 90.44 & 9.32 \\
\hline
\end{tabular}

\subsection{The effect of the intervention on stress, systolic and diastolic blood pressure}

Progressive muscle relaxation with classical music had significant effect on stress $(p=.0001)$, progressive muscle relaxation had a significant effect on stress $(p=.010)$, but without treatment, it did not show an effect on stress $(p=.758)$ in hypertensive women, where the three groups of stress measurements used $t$-test.

Progressive muscle relaxation with classical music had a significant impact on systolic blood pressure $(p=.0001)$, and only in progressive muscle relaxation also showed the impact on systolic ( $p=.003)$, likewise without treatment still showed the effect on systolic $(p=.013)$ through the Wilcoxon test.

Progressive muscle relaxation with classical music had a significant effect on diastolic blood pressure $(p=.0001)$, and only with progressive muscle relaxation also showed the impact on diastolic $(p=.006)$, but without intervention did not affect diastolic ( $p=.123$ ) using the Wilcoxon test (see Table $3)$.

With the Oneway Anova test, the stress variable gave a significant difference in the three groups $(p=.005)$. Meanwhile, the systolic blood pressure also had a significant difference ( $p=.009)$ with the Kruskal-Wallis test. Diastolic pressure was found to be no significant difference for the three groups $(p=.500)$ through the Kruskal-Wallis test (see Table 4).

Table 3. Effects of progressive muscle relaxation with and without classical music on stress and blood pressure

\begin{tabular}{lll}
\hline Effect & $\begin{array}{l}\text { Mean } \\
\text { Differences }\end{array}$ & $\boldsymbol{p}$ \\
\hline Stress before and after intervention in group I & 5.11 & .0001 \\
Systolic before and after intervention in group I & 5.23 & .0001 \\
Diastolic before and after intervention in group I & 4.67 & .0001 \\
Stress before and after intervention in group II & 1.31 & .010 \\
Systolic before and after intervention in group II & 2.95 & .003 \\
Diastolic before and after intervention in group II & 2.76 & .006 \\
Stress before and after intervention in group III & +0.194 & .758 \\
Systolic before and after intervention in group I & 2.48 & .013 \\
Diastolic before and after intervention in group I & 1.54 & .123 \\
\hline
\end{tabular}

Table 4. Difference in stress, blood pressure of respondents who gets progressive muscle relaxation with and without classical music and who did not get treatment

\begin{tabular}{lll}
\hline Variable & Mean Rank & $\boldsymbol{p}$ \\
\hline \multirow{3}{*}{ Stress } & 18.22 & \\
& 16.78 & .005 \\
& 19.31 & \\
Systolic & 41.96 & .009 \\
& 57.78 & \\
& 63.76 & \\
Diastolic & 50.29 & .500 \\
& 54.25 & \\
\hline
\end{tabular}

\section{Discussion}

The study aimed to investigate the effect of progressive muscle relaxation with and without classical music on stress and blood pressure in hypertension women. From the existing findings, it can be suggested based on statistical test data that progressive muscle relaxation with classical music provided a greater contribution in controlling stress and blood pressure in hypertensive women.

The study showed that more women were older, married, primary school education, low income, housewives, have hypertension for less than 1 year. The study also reported that the average stress score both before and after the intervention in the three groups according to Cohen, ${ }^{[25]}$ was moderate stress. The results of the study showed according to the AHA 2020 that almost the overall average systolic blood pressure was at grade I Hypertension, while the average diastolic scores were at grade I. ${ }^{[27]}$

Group 2 treatment received 1 package of progressive muscle relaxation exercises accompanied by classical music from 
Bach and group I treatment received 1 package of progressive muscle relaxation exercise only. Of the 2 types of groups, not a single participant in each training session stated that stress symptoms experienced were getting increasing. When compared with the two groups, satisfaction and reduced tension were more frequently described in the 2 treatment groups.

Studies showed that progressive muscle relaxation with and without classical music influenced stress. But without both, it did not have a meaningful effect. And also showed that progressive muscle relaxation with classical music had a real and greater impact on reducing stress than without classical music with the Oneway Anova test. This can be seen from the effect test and the difference in the mean score in each group.

One study stated that progressive muscle relaxation can lead to a reduction in stress and blood pressure as evidenced by a significant difference in mean and a significant effect. ${ }^{[14]}$ Another study also showed that stress also decreased after listening to music five times a day. ${ }^{[28]}$ One study also noted a similar conclusion that listening to calming music affects the stress response domain differently for each individual. ${ }^{[29]}$ From other studies that support this research, it was stated that Bach music was one of the few kinds of classical music that were effective for improving the quality of life and health of individuals and even possibly extending one's life. ${ }^{[30]}$

Stress is a risk factor that can increase blood pressure. Various ways are needed to control these stressful conditions to help control blood pressure. It can be concluded that progressive muscle relaxation and classical music contribute more to controlling blood pressure than progressive muscle relaxation alone or with medication alone. If there was no effort made by the individual to control her stress, the increased blood pressure experiences will be uncontrollable.

Our findings illustrate the effect in three groups who received progressive muscle relaxation with and without classical music and the control group on systolic blood pressure in women patients with hypertension.

It was found that the effect of changes in systolic blood pressure was greater using progressive muscle relaxation intervention with classical music.

Controlling blood pressure in hypertensive patients requires two major parts of intervention in the form of pharmacological or non-pharmacological interventions, ${ }^{[31]}$ intervention without treatment, one of which can be in the form of stress control, ${ }^{[32]}$ through progressive muscle relaxation with and without classical music.

As initial therapy, medication can reduce blood pressure in

Published by Sciedu Press patients with mild and moderate hypertension. ${ }^{[33]}$ However, it will be better with the use of behavioral interventions. ${ }^{[34]}$ Blood pressure management with progressive muscle relaxation and classical music gave a greater contribution to lowering systolic blood pressure in women using antihypertensive drugs.

Several studies have shown a significant effect of progressive muscle relaxation on lowering systolic blood pressure. ${ }^{[13,14]}$ Separately through other studies, Bach music contributes to blood pressure. ${ }^{[23,30]}$

The study showed the effect of progressive muscle relaxation and classical music with and without in diastolic blood pressure in women with hypertension, and the control group, there was no significant effect. Although progressive muscle relaxation with classical music affected, it did not show a significant difference in the effect of the three patient groups.

Statistically, pharmacological interventions have not been able to reduce blood pressure in the group that did not receive progressive muscle relaxation treatment with and without classical music. However, when viewed from the difference between the mean before and after the intervention period, it showed a decrease in diastolic blood pressure.

Based on the analysis of variance, there was no significant difference in diastolic reduction between the three treatments. However, from the $t$-test, it can be concluded that progressive muscle relaxation with classical music provides a greater chance of controlling diastolic blood pressure than without music classic or if the only medication was given.

Several studies showed that women suffer from hypertension more than men. ${ }^{[35,36]}$ The use of antihypertensive drugs and patient compliance in consuming them is needed in hypertensive patients and causes increased blood pressure control. ${ }^{[37,38]}$ However, the use of antihypertensive drugs will be better when accompanied by progressive muscle relaxation. ${ }^{[14,39]}$ Blood pressure control will be even better when combined with the use of classical music.

This study has several limitations. The absence of random sampling in the three groups. Another thing was that participants had diverse characteristics such as education, occupation, and income which has provided opportunities for differences for each participant in implementing the interventions given. This study was conducted during the Covid 19 pandemic, so it required extra caution and a longer time in collecting patient data.

\section{Conclusion}

This study can provide input to strengthen science on hypertension nursing care in particular for a group of women with 
a non-pharmacological approach. The progressive muscle relaxation intervention accompanied by classical music from Bach had a statistically significant effect on controlling stress and blood pressure in female hypertensive patients. The results obtained can be proposed as an addition to the nursing action program at the Public Health Center as a complemen- tary therapy in hypertension nursing care that can easily be used.

\section{CONFlicts OF InTEREST Disclosure}

The authors declare that there are no competing or potential conflicts of interest.

\section{REFERENCES}

[1] Katherine T. Mills ASJH. The global epidemiology of hypertension. Nat Rev Nephrol. 2020; 16: 223-237. PMid:32024986 https : //doi.org/10.1038/s41581-019-0244-2

[2] WHO. Hypertension [Internet]. WHO; 2019. Available from: https://www . who. int/news-room/fact-sheets/detail/h ypertension\#: : text=Anestimated1.13billionpeople, causeof prematuredeathworldwide

[3] World Health Organization. A global brief on Hypertension - World Health Day 2013. World Health Organization. 2013.

[4] WHO. Global status report on NCDs 2014. WHO. 2014.

[5] Kang AW, Dulin A, Nadimpalli S, et al. Stress, adherence, and blood pressure control: A baseline examination of Black women with hypertension participating in the SisterTalk II intervention. Prev Med Reports. 2018.

[6] Sudaryanto S, Rahardjo SS, Indarto D. Risk Factors of Hypertension among Women in Sragen, Central Java. J Epidemiol Public Heal. 2019. https://doi.org/10.26911/theicph.2019.01.09

[7] Yaribeygi H, Panahi Y, Sahraei H, et al. The impact of stress on body function: A review. EXCLI Journal. 2017.

[8] Puzserova A, Bernatova I. Blood pressure regulation in stress: Focus on nitric oxide-dependent mechanisms. Physiological Research. 2016. PMid:27775419 https://doi .org/10.33549/physiolre s. 933442

[9] Schneiderman N, Ironson G, Siegel SD. Stress and health: Psychological, behavioral, and biological determinants. Annual Review of Clinical Psychology. 2005. PMid:17716101 https://doi .org/10 .1146/annurev.clinpsy.1.102803.144141

[10] Spruill TM. Chronic psychosocial stress and hypertension. Current Hypertension Reports. 2010. PMid:20425153 https ://doi .org/ 10.1007/s11906-009-0084-8

[11] Spruill TM, Butler MJ, Thomas SJ, et al. Association Between High Perceived Stress Over Time and Incident Hypertension in Black Adults: Findings From the Jackson Heart Study. J Am Heart Assoc. 2019.

[12] Firmino EMS, Kuntze LB, Lagatta DC, et al. Effect of chronic stress on cardiovascular and ventilatory responses activated by both chemoreflex and baroreflex in rats. J Exp Biol. 2019.

[13] VK, SDA, RP. Effectiveness of Progressive Muscle Relaxation Technique on Stress and Blood Pressure among Elderly with Hypertension. IOSR J Nurs Heal Sci. 2014.

[14] Hanif SA, Boru GA. The influence of progressive muscle relaxation on stress, blood pressure, and quality of life in hypertension patients in the working area of Muliorejo Puskesmas, deli Serdang regency. Int J Adv Nurs Stud. 2018.

[15] Sheu S, Irvin BL, Lin HS, et al. Effects of Progressive Muscle Relaxation on Blood Pressure and Psychosocial Status for Clients with Essential Hypertension in Taiwan. Holist Nurs Pract. 2003.
[16] Kow FP, Adlina B, Sivasangari S, et al. The impact of music guided deep breathing exercise on blood pressure control - A participant blinded randomised controlled study. Med J Malaysia. 2018.

[17] Kühlmann AYR, Etnel JRG, Roos-Hesselink JW, et al. Systematic review and meta-analysis of music interventions in hypertension treatment: A quest for answers. BMC Cardiovasc Disord. 2016. PMid:27095510 https://doi.org/10.1186/s12872-016-024 4-0

[18] Vescelius EA. Music and health. Music Q. 1918. https://doi.or $\mathrm{g} / 10.1093 / \mathrm{mq} / \mathrm{IV} .3 .376$

[19] Modesti PA, Ferrari A, Bazzini C, et al. Psychological predictors of the antihypertensive effects of music-guided slow breathing. $\mathrm{J}$ Hypertens. 2010.

[20] Saing SK, Rina O, Ramayati R, et al. Effect of classical music on reducing blood pressure in children. Paediatr Indones. 2016.

[21] Libby P. Johann Sebastian Bach: A Healer in His Time. Circ Res. 2019;

[22] Schueller HM, Forkel JN. Johann Sebastian Bach, His Life, Art, and Work. J Aesthet Art Crit. 1971. https://doi.org/10.2307/42 9558

[23] Trappe HJ, Breker IM. Differential effects of Bach's Orchestral Suite No. 3 on blood pressure and heart rate - a prospective controlled study. Music Med. 2018.

[24] Zhou K, Li X, Li J, et al. A clinical randomized controlled trial of music therapy and progressive muscle relaxation training in female breast cancer patients after radical mastectomy: Results on depression, anxiety and length of hospital stay. Eur J Oncol Nurs. 2015.

[25] Cohen S. Perceived tress cale. Psychology. 1994.

[26] Purnami CT, Suwondo A, Sawitri DR, et al. Psychometric measurement of perceived stress among midwives at primary health care province of central java indonesia. Indian J Public Heal Res Dev. 2019; 10(3): 804-9. https://doi.org/10.5958/0976-5506. 20 19.00600 .4

[27] Unger T, Borghi C, Charchar F, et al. 2020 International Society of Hypertension Global Hypertension Practice Guidelines. Hypertension. 2020.

[28] Linnemann A, Strahler J, Nater UM. The stress-reducing effect of music listening varies depending on the social context. Psychoneuroendocrinology. 2016. PMid:27393906 https://doi .org/10.1 016/j · psyneuen . 2016.06.003

[29] Thoma MV, La Marca R, Brönnimann R, et al. The Effect of Music on the Human Stress Response. PLoS One. 2013.

[30] Trappe HJ. The effects of music on the cardiovascular system and cardiovascular health. Heart. 2010.

[31] Kimani S, Mirie W, Chege M, et al. Association of lifestyle modification and pharmacological adherence on blood pressure control among patients with hypertension at Kenyatta National Hospital, Kenya: A cross-sectional study. BMJ Open. 2019. 
[32] Mahmood S, Shah KU, Khan TM, et al. Non-pharmacological management of hypertension: in the light of current research. Irish Journal of Medical Science. 2019.

[33] Webster R, Salam A, De Silva HA, et al. Fixed low-dose triple combination antihypertensive medication vs usual care for blood pressure control in patients with mild to moderate hypertension in Sri Lanka a randomized clinical trial. JAMA - J Am Med Assoc. 2018.

[34] Izeogu C, Kalinowski J, Schoenthaler A. Strategies to Improve Adherence to Anti-Hypertensive Medications: a Narrative Review. Current Hypertension Reports. 2020.

[35] Das Gupta R, Shabab Haider S, Sutradhar I, et al. Gender differences in hypertension awareness, antihypertensive use and blood pressure control in Nepalese adults: Findings from a nationwide cross-sectional survey. J Biosoc Sci. 2019. PMid:31466532 https : //doi.org/10.1017/S0021932019000531
[36] Khayyat SM, Khayyat SMS, Hyat Alhazmi RS, et al. Predictors of medication adherence and blood pressure control among Saudi hypertensive patients attending primary care clinics: A cross-sectional study. PLoS One. 2017.

[37] Lakatta EG, AlunniFegatelli D, Morrell CH, et al. Impact of Stiffer Arteries on the Response to Antihypertensive Treatment: A Longitudinal Study of the SardiNIA Cohort. J Am Med Dir Assoc. 2020.

[38] Vrijens B, Antoniou S, Burnier M, et al. Current situation of medication adherence in hypertension. Frontiers in Pharmacology. 2017.

[39] Schneider RH, Alexander CN, Staggers F, et al. A randomized controlled trial of stress reduction in African Americans treated for hypertension for over one year. Am J Hypertens. 2005. PMid:15691622 https://doi.org/10.1016/j.amjhyper.2004.08.027 